Article

\title{
Dispersion Process and Effect of Oleic Acid on Properties of Cellulose Sulfate- Oleic Acid Composite Film
}

\author{
Guo Chen *, Bin Zhang and Jun Zhao \\ Department of Biotechnology and Bioengineering, Huaqiao University, Xiamen 361021, China; \\ E-Mails: zhangbinzbgg@126.com (B.Z.); zhaojun@hqu.edu.cn (J.Z.) \\ * Author to whom correspondence should be addressed; E-Mail: chenguo@hqu.edu.cn; \\ Tel.: +86-592-616-2347; Fax: +86-592-616-2300.
}

Academic Editor: Carla Renata Arciola

Received: 22 March 2015 / Accepted: 17 April 2015 / Published: 30 April 2015

\begin{abstract}
The cellulose sulfate (CS) is a newly developed cellulose derivative. The work aimed to investigate the effect of oleic acid (OA) content on properties of CS-OA film. The process of oleic acid dispersion into film was described to evaluate its effect on the properties of the film. Among the formulations evaluated, the OA addition decreased the solubility and water vapor permeability of the CS-OA film. The surface contact angle changed from $64.2^{\circ}$ to $94.0^{\circ}$ by increasing CS/OA ratio from 1:0 to 1:0.25 (w/w). The TS increased with OA content below $15 \%$ and decreased with OA over $15 \%$, but the $\varepsilon$ decreased with higher OA content. The micro-cracking matrices and micro pores in the film indicated the condense structure of the film destroyed by the incorporation of oleic acid. No chemical interaction between the OA and CS was observed in the XRD and FTIR spectrum. Film formulation containing $2 \%(\mathrm{w} / \mathrm{w}) \mathrm{CS}, 0.3 \%(\mathrm{w} / \mathrm{w})$ glycerol and $0.3 \%(\mathrm{w} / \mathrm{w}) \mathrm{OA}$, showed good properties of mechanic, barrier to moisture and homogeneity.
\end{abstract}

Keywords: packaging film; cellulose sulfate; oleic acid; composite films; hydrophobic properties

\section{Introduction}

Film and coating based on biomaterials as an alternative packaging draws lots of attention because of the consumers' demand for high quality foods and increased awareness of environmental issues [1]. 
The commonly used biomaterials are comprised of proteins, polysaccharides, lipids, and other degradable biomaterials [2].

Cellulose is D-glucopyranose unit of conformation chair bonded through $\beta(1 \rightarrow 4)$ glycosidic linkages. Cellulose ethers are a class of semi-synthetic polymers obtained by derivatization of the hydroxyl groups at positions 2, 3, and/or 6 of the anhydroglucose residues of cellulose. Hydroxypropylmethyl cellulose (HPMC), carboxymethyl cellulose (CMC) and methyl cellulose (MC) as derivatives with improved solubility have long been used in fiber, film and gel-based materials [3]. Films made from cellulose derivatives showed good tensile resistance and effective barrier against $\mathrm{O}_{2} / \mathrm{CO}_{2}$ [4,5]. Nonetheless, edible films prepared from cellulose derivatives do not act as an efficient water vapor barrier due to the hydrophilic nature of cellulose [6-8]. Cellulose nanocrystals (CNC) synthesized from microcrystalline cellulose by a sulfuric acid hydrolysis was added to PLA or PLA-PHB film to improve the thermal stability of the film and reduce water permeability of the film $[9,10]$. One method to improve the water vapor barrier of cellulose films is incorporation of hydrophobic substances (fatty acids, beeswax, lipids) into the hydrocolloid matrix either by emulsification of hydrophobic substances and hydrocolloid aqueous solution before drying to obtain film, or the formation of bilayer films with a hydrophobic layer over the hydrocolloid based film. Many authors have studied the influence of hydrophobic substances addition on the properties of edible films [11-15]. Some researchers applied edible film based on composites of cellulose derivatives and hydrophobic substances to the fruit coating [16].

Cellulose sulfate (CS), prepared by partial or complete substitution of the 6-hydroxyl groups $(-\mathrm{OH})$ with sulfate group $\left(-\mathrm{SO}_{3} \mathrm{H}\right)$, is a newly developed cellulose derivatives for several medical and biotechnological applications because of its biocompatibility and easy biodegradability [17-19]. According to our previous study [20,21], the film based on CS had poor water vapor barrier due to its excellent solubility. It is important to increase the water vapor barrier of the CS based packaging film for extending its application. Hydrocolloids films incorporation of lipid can result in better functionality than films of single component. Glycerol was also used in film as one of the most popular plasticizers used in film-making techniques, due to stability and compatibility with hydrophilic bio-polymer [22]. The objective of this work was to evaluate the influence of oleic acid incorporation into CS film on the mechanical, optical, structural, and water vapor barrier properties of CS films as compared with the pure CS films, using glycerol as plasticizer.

\section{Results and Discussion}

\subsection{Rheological Behavior of the Film-Forming Emulsions}

The viscosity of film-forming solution is important to avoid non-uniform in thin liquid film after coating. As shown in Figure 1, the viscosity of the CS/OA blends increased from $346 \mathrm{mPa} \cdot \mathrm{s}^{-1}$ to $423 \mathrm{mPa} \cdot \mathrm{s}^{-1}$ when the OA content varied from $0 \%$ to $25 \%$. The emulsion viscosity is influenced by various factors, mainly by the continuous phase viscosity, interfacial film viscosity and droplet size [23]. In this work, the interfacial film viscosity was same to the continuous phase viscosity, because all of the emulsions were prepared with the same CS content under the same homogenization conditions. The variation of emulsion viscosity was mainly attributed to oil droplet size caused by variation of OA content in emulsion and the homogenization velocity. The $\mathrm{O} / \mathrm{W}$ and $\mathrm{W} / \mathrm{O} / \mathrm{W}$ were possible oil-in-water 
structure, but $\mathrm{O} / \mathrm{W}$ was more stable. In $\mathrm{O} / \mathrm{W}$ structure, hydrogen bond formed between carboxyl $(-\mathrm{COOH})$ of oleic acid and hydroxyl $(-\mathrm{OH})$ of cellulose sulfate as shown in Graph 1. Generally, the size distributions of oil droplet in $\mathrm{O} / \mathrm{W}$ emulsions were trimodal with peak maximum, respectively, at $0.2 \mu \mathrm{m}$ (I), $10 \mu \mathrm{m}$ (II) and $100 \mu \mathrm{m}$ (III), in which the predominance was population II according to previous research $[23,24]$. The number of droplet population increased with OA addition, which lead to the viscosity increasing due to the enhanced contact probability between $\mathrm{O} / \mathrm{W}$ interfacial area and coaxial cylinder of viscometer. When OA content reached a critical value, the number of droplet do not increase any more at the same homogenization conditions, whereas the size of droplet increased due to the coalescence of droplets. Hence, the OA content over critical value would decrease the homogeneity of the $\mathrm{O} / \mathrm{W}$ emulsion; correspondingly, the structure of the film became uneven.

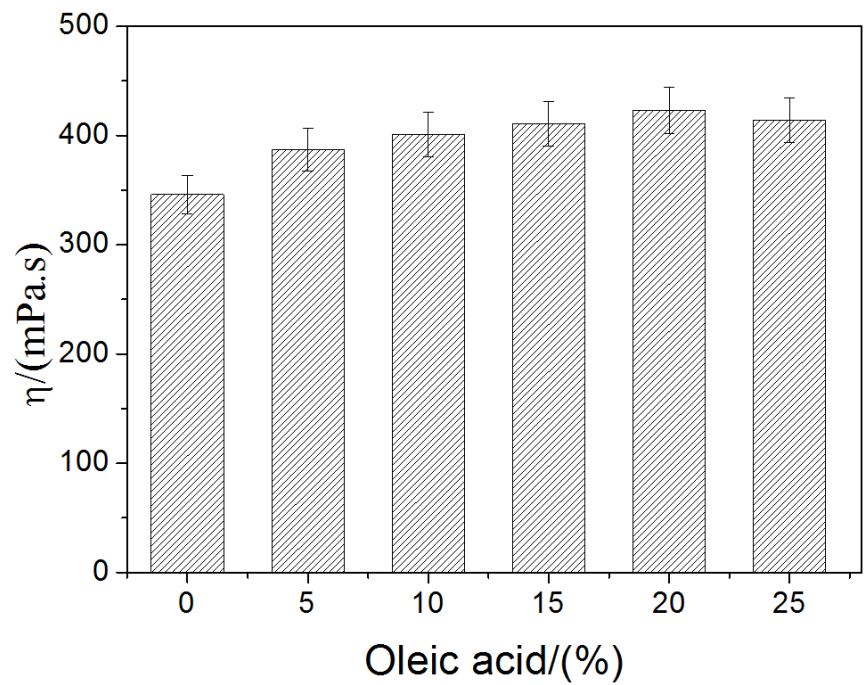

Figure 1. The effect of oleic acid on the viscosity of film forming emulsions.
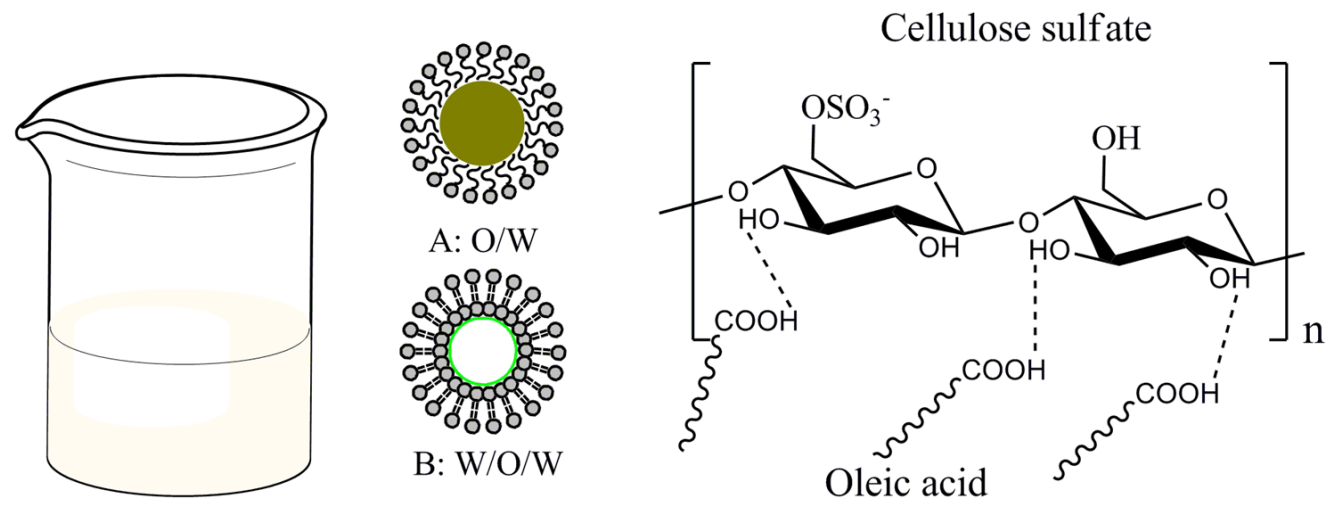

Hydrophilic end ens Hydrophobic end

Graph 1. The schematic for emulsion of oleic acid, cellulose sulfate, glycerol and water.

\subsection{Microstructure of CS-OA Films}

The morphology of the CS film and composite film (CS $+25 \% \mathrm{OA})$ are compared in Figure 2 to investigate their microstructure. The surface of CS film and composite film were smooth. The circle splotch of different size on the film surface in Figure 2B and C was observed. It should be the function 
of the OA diffusion on the surface. The splotch formation was accompanied with the CS-OA film formation during water evaporating, as shown in Figure 2F. During water evaporating, the oil droplet in film emulsion will move down with the liquid level. The intermolecular distance of CS becomes closer with the decreasing of water content in emulsion; the hydrogen bonds between CS molecules were strong enough to prevent the oil droplet moving in film emulsion. Pressure at $\mathrm{O} / \mathrm{W}$ interface increased dramatically with the water continuous evaporation, especially near the interface of the film, correspondingly spherical droplet became ellipsoidal and oil accelerated diffusion into the film matrix over time, like a droplet of oil on paper. Though the number of 100- $\mu \mathrm{m}$ (III) droplets was small, it definitely diffuses at film surface, because its size was much bigger than thickness of the film. Therefore, more large-size splotches were observed in film surface, as shown in Figure 2. Fabra et al. [25] reported that the lipid particle size in the film emulsion containing 1-carrageenan, glycerol and lipids mixtures of oleic acid (OA)/beeswax (BW) varied from 4.3 to $20.3 \mu \mathrm{m}$ with the ratio variation between OA and BW lipid. Nevertheless, Ghasemlou et al. [26] reported that the $\mathrm{D}_{3,2}$ (volume-surface mean diameter) of lipid particles in composite film emulsion based on kefiran and oleic acid (OA) varied from $1.13 \mu \mathrm{m}$ to $2.06 \mu \mathrm{m}$. The results were quite different from each other. In our research, the lipid particle was not observed in the surface microstructure and the size of splotch on surface varied from $\sim 10$ to $\sim 50 \mu \mathrm{m}$, according to Figure 2. Limpisophon et al. [27] also indicated that the films with oleic acid did not have crystalline particles like films with stearic acid, since oleic acid is in a liquid state at room temperature (m.p. $=13-14{ }^{\circ} \mathrm{C}$ ) in edible films based on blue shark (Prionace glauca) skin gelatin. Cross-section images of CS films and CS-OA films with 25\% OA are compared in Figure 2, in which the cross-sectional microstructure of CS-OA composite film was rougher than that of CS film. The CS-OA blend film also showed micro-cracking matrices and micro pores of different shapes and sizes, which meant the condense structure of film destroyed by the incorporation of oleic acid. The main pore size was $0.2 \mu \mathrm{m}$ (I) according to Figure 2E, which was different from the droplet size in emulsion reported $[23,24]$.
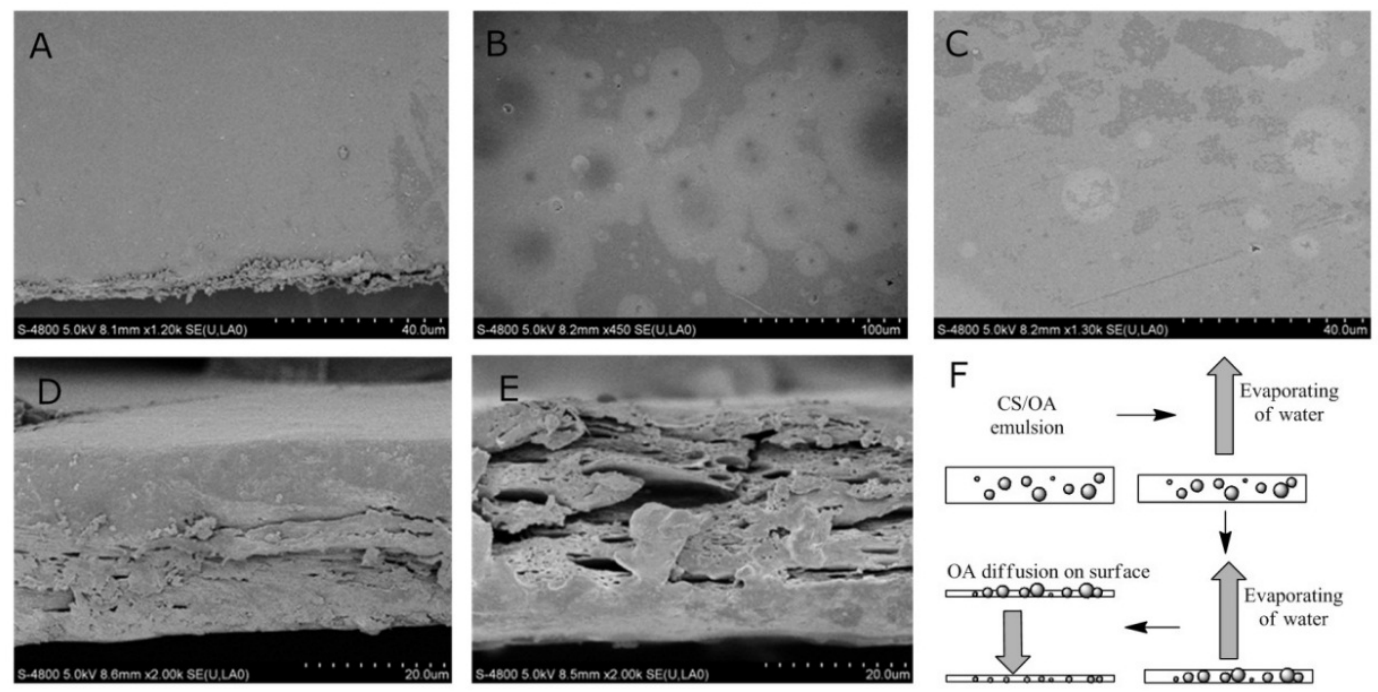

Figure 2. Surface appearance and cross-section appearance of films; surface of CS film (A); CS $+25 \%$ OA film (B); CS $+25 \%$ OA film (C) and cross section of CS film (D); $\mathrm{CS}+25 \% \mathrm{OA}$ film $(\mathbf{E})$; and process of CS-OA film formation during water evaporating $(\mathbf{F})$. 


\subsection{Surface Water Contact Angle of CS-OA Films}

Contact angle is the angle $(\theta)$ between film surface and tangent at the droplet-film intersection. It can be used to indicate the hydrophobicity of the surface or the wettability of polymers [28]. The contact image between water droplet and CS-OA film at 0, 30, and $120 \mathrm{~min}$ is shown in Figure 3. The initial water contact angle for CS-OA film was $94^{\circ}$, whereas the water contact angle for pure CS film is $64.2^{\circ}$. Therefore the inclusion of OA in CS film increased the hydrophobicity. The droplet gradually permeated into film through the CS matrix. After $30 \mathrm{~min}$ the droplet left became small. After $120 \mathrm{~min}$, some water unabsorbed was still observed on the surface of CS-OA films, compared with soluble hole formed on the film surface after $60 \mathrm{~s}$ for pure CS film [21]. This indicated that CS-OA film was less rapidly wetted, which explained the decreasing water solubility of CS-OA films as shown in Table 1.

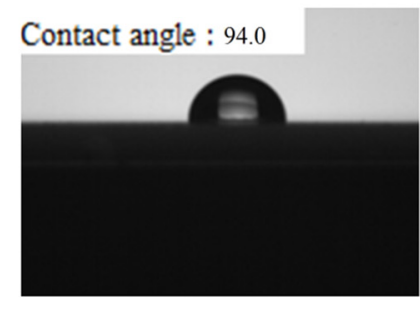

(a) 0 min

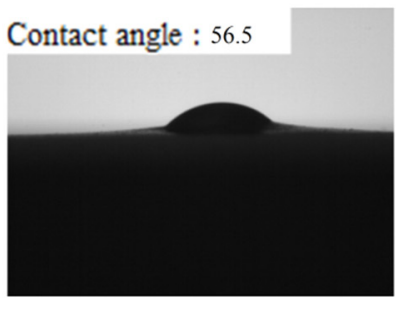

(b) $30 \mathrm{~min}$

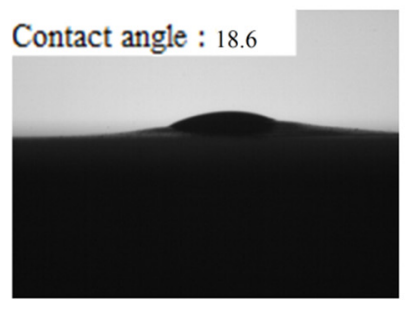

(c) $120 \mathrm{~min}$

Figure 3. Surface water contact angle of oleic acid-cellulose sulfate films (CS $+25 \% \mathrm{OA}$ film).

\subsection{The Effect of Oleic Acid Content on Properties of CS-OA Films}

Some properties of CS-OA films with different OA content, such as the thickness, flexibility, integrity, water solubility, oil permeability, transparency, mechanical properties and water vapor permeability are shown in Table 1 . The integrity and folding property of all films are good, which was consistent with their easy peeling from the Teflon surface. The thickness, solubility and oil permeability of the CS-OA films did not change significantly under different OA content. The solubility and the transparency of composite films decreased gradually with addition of OA in film-forming emulsion, correspondingly the thickness of composite films and oil permeability increased with the OA content. The increasing of oil permeability can be attributed to the tunnel provided by the OA in the film. 
Table 1. The effects of OA content on properties of oleic acid-cellulose sulfate films.

\begin{tabular}{|c|c|c|c|c|c|c|c|c|c|}
\hline Sample & $\delta(\mu \mathrm{m})$ & Inte & Fold & S (h) & OP (\%) & $\mathrm{T}(\%)$ & TS (MPa) & $\varepsilon(\%)$ & $\begin{array}{l}\mathrm{WVP} \times 10^{-11} \\
\left(\mathrm{gm}^{-1} \mathrm{~s}^{-1} \mathrm{~Pa}^{-1}\right)\end{array}$ \\
\hline $2 \mathrm{~g} \mathrm{CS}+0.3 \mathrm{~g}$ Gly & $25.00 \pm 0.16^{\mathrm{a}}$ & good & good & $0.02 \pm 0.01^{\mathrm{a}}$ & $0.2 \pm 0.1 \%{ }^{a}$ & $89.3 \pm 3.2^{a}$ & $14.5 \pm 1.5^{\mathrm{a}}$ & $27.9 \pm 0.8^{\mathrm{a}}$ & $3.92 \pm 0.23^{\mathrm{a}}$ \\
\hline $2 \mathrm{~g} \mathrm{CS}+0.3 \mathrm{~g} \mathrm{Gly}+0.1 \mathrm{~g} \mathrm{OA}$ & $25.02 \pm 0.10^{\mathrm{a}}$ & good & good & $1.50 \pm 0.10^{b}$ & $0.2 \pm 0.2 \%^{\mathrm{a}}$ & $85.0 \pm 5.6^{\mathrm{a}}$ & $28.2 \pm 2.1^{b}$ & $18.6 \pm 0.6^{b}$ & $3.49 \pm 0.21^{\mathrm{a}}$ \\
\hline $2 \mathrm{~g} \mathrm{CS}+0.3 \mathrm{~g} \mathrm{Gly}+0.2 \mathrm{~g} \mathrm{OA}$ & $25.85 \pm 0.18^{b}$ & good & good & $2.33 \pm 0.08^{c}$ & $1.9 \pm 0.2 \%^{\mathrm{b}}$ & $76.9 \pm 2.8^{b}$ & $37.1 \pm 1.7^{\mathrm{c}}$ & $13.9 \pm 0.3^{\mathrm{a}}$ & $2.41 \pm 0.16^{b}$ \\
\hline $2 \mathrm{~g} \mathrm{CS}+0.3 \mathrm{~g} \mathrm{Gly}+0.3 \mathrm{~g} \mathrm{OA}$ & $29.04 \pm 0.12^{c}$ & good & good & $4.45 \pm 0.12^{\mathrm{d}}$ & $9.0 \pm 0.3 \%^{\mathrm{c}}$ & $73.5 \pm 4.8^{b}$ & $43.5 \pm 1.3^{d}$ & $9.2 \pm 0.5^{\mathrm{d}}$ & $1.91 \pm 0.12^{b c}$ \\
\hline $2 \mathrm{~g} \mathrm{CS}+0.3 \mathrm{~g} \mathrm{Gly}+0.4 \mathrm{~g} \mathrm{OA}$ & $36.60 \pm 0.26^{d}$ & good & good & $5.13 \pm 0.50 \mathrm{de}$ & $14.6 \pm 0.5 \%{ }^{\mathrm{d}}$ & $67.4 \pm 2.3^{\mathrm{c}}$ & $36.8 \pm 1.5^{\mathrm{e}}$ & $7.2 \pm 0.3^{\mathrm{e}}$ & $1.57 \pm 0.21^{\mathrm{c}}$ \\
\hline $2 \mathrm{~g} \mathrm{CS}+0.3 \mathrm{~g} \mathrm{Gly}+0.5 \mathrm{~g} \mathrm{OA}$ & $55.20 \pm 0.32^{\mathrm{e}}$ & good & good & $5.55 \pm 0.36^{\mathrm{e}}$ & $25.1 \pm 0.8 \%{ }^{\mathrm{e}}$ & $68.2 \pm 3.1^{\mathrm{c}}$ & $34.3 \pm 2.2^{\mathrm{e}}$ & $6.4 \pm 0.5^{\mathrm{e}}$ & $1.52 \pm 0.14^{\mathrm{c}}$ \\
\hline
\end{tabular}

$\delta$ : thickness; Inte: integrity; Fold: folding properties; S: solubility time; OP: oil permeability; T: transparency; TS: tension strength; $\varepsilon$ : elongation at break; WVP: water vapor permeability; Mean \pm standard deviation. Different letters represent significant differences $(p<0.05)$ according to the LSD test. 
The ability of the coating to form a continuous layer over the product and the durability of the film are important, which can be reflected partly by mechanical properties listed in Table 1 . The TS increased, but the $\varepsilon$ decreased, when increasing OA content below 15\%. The high TS and low $\varepsilon$ indicated stronger and less extendible films. OA content over $15 \%$ decreased the values of all mechanical parameters, forming weaker and less extendible films. Elongation of CS-OA film significantly $(p<0.05)$ decreased when oleic acid was incorporated into the CS matrix, which has already been reported in other hydrocolloids films containing lipids [29-31]. It was explained by the fact that lipids were unable to form a cohesive and continuous matrix in the film. Oleic acid has also been reported to increase elongation of soy protein, corn zein, egg white and HPMC films [13,32,33]. They explained this as a plasticizing effect of unsaturated oleic acid. The effect of lipids on mechanical of hydrocolloids film may be dependent on the basic matrix properties of biomaterials, the interaction of the polymer molecular, the component of the film and the size distribution of the lipid droplet.

The WVP values of the CS-OA emulsified films are presented in Table 1. As expected, the water vapor permeability decreased when the OA content increased. Incorporation of fatty acids caused a significant difference $(p<0.05)$ between the WVP of the CS films containing different OA content. The WVP of hydrocolloids-fatty acid films decreased as the content of fatty acids increased. The WVP decreased from $3.92 \times 10^{-11}$ to $1.52 \times 10^{-11} \mathrm{gm}^{-1} \mathrm{~s}^{-1} \mathrm{~Pa}^{-1}$ as OA content reached $25 \%$ of the CS in the CS-OA film. The OA dispersed in the CS film decreased the practical interfacial area exposed to water vapor. In general, the relative polarity of the support polymer and the type of lipid has the strongest influence on the water vapor barrier of emulsified films. Similar results were obtained by other researches [34-36]. However, as the amounts of fatty acids increased from $20 \%$ to $25 \%$, no significant differences $(p>0.05)$ in the WVP values among the emulsified films were observed. Fabra et al. [37] showed that when the beeswax content added came to over $30 \%$ of the total lipid phase (70:30 OA:BW relationship) no further reduction in the WVP of sodium caseinate films was observed. The poor dispersion of lipid in the film system with the increasing lipid content may be account for the result. Size, distribution and physical state of the lipid, and polymorphism also seem to play a role in WVP, especially when the lipid content is over a critical value.

\subsection{The Interactions among Components of Edible Film}

When two or more substances are mixed, physical blends versus chemical interactions can be reflected by the changes in characteristic spectra peaks [38]. FTIR spectra of the CS film with different OA content are shown in Figure 4. The assignments proposed for the bands observed were annotated. The strong broad band observed in the $3500-3000 \mathrm{~cm}^{-1}$ range was attributable to hydrogen bond between different $\mathrm{O}-\mathrm{H}$ groups from $\mathrm{OH}$ of glucosidic ring, $\mathrm{OH}$ carboxylic function of oleic acid acids and $\mathrm{OH}$ of glycerol. A strong broad band at $1207 \mathrm{~cm}^{-1}$ was attributed to the $-\mathrm{O}-\mathrm{SO}_{3}{ }^{-}$stretching mode. A strong and composite band with a maximum intensity at $1066 \mathrm{~cm}^{-1}$ was assigned to the stretching mode of the $\mathrm{C}-\mathrm{O}$ bond. A medium weak band at $2949 \mathrm{~cm}^{-1}$ was assignable to $\mathrm{C}-\mathrm{H}$ stretching mode, which was more intense for CS-OA film than that for pure CS film. Several medium bands in the region $1400-1200 \mathrm{~cm}^{-1}$ was assigned to the $\mathrm{C}-\mathrm{H}$ bending and wagging modes, and $\mathrm{O}-\mathrm{H}$ bending mode. A weak band at $807 \mathrm{~cm}^{-1}$ was assigned to the stretching mode of the glucosidic ring from CS. The new frequency at $2853 \mathrm{~cm}^{-1}$ for CS-OA film was attributed to the $\mathrm{C}-\mathrm{H}$ stretching mode of the aliphatic chain of the fatty 
acids. The intense IR band at $1702 \mathrm{~cm}^{-1}$ and $1620 \mathrm{~cm}^{-1}$ corresponded to $\mathrm{C}=\mathrm{O}$ and $\mathrm{COO}^{-}$stretching mode of oleic acid, respectively. These characteristic peaks of fatty acids only appeared in the CS-OA composite films. No additional chemical grouping was found on the FTIR spectra, which indicated no chemical bond formed between the lipid and CS.

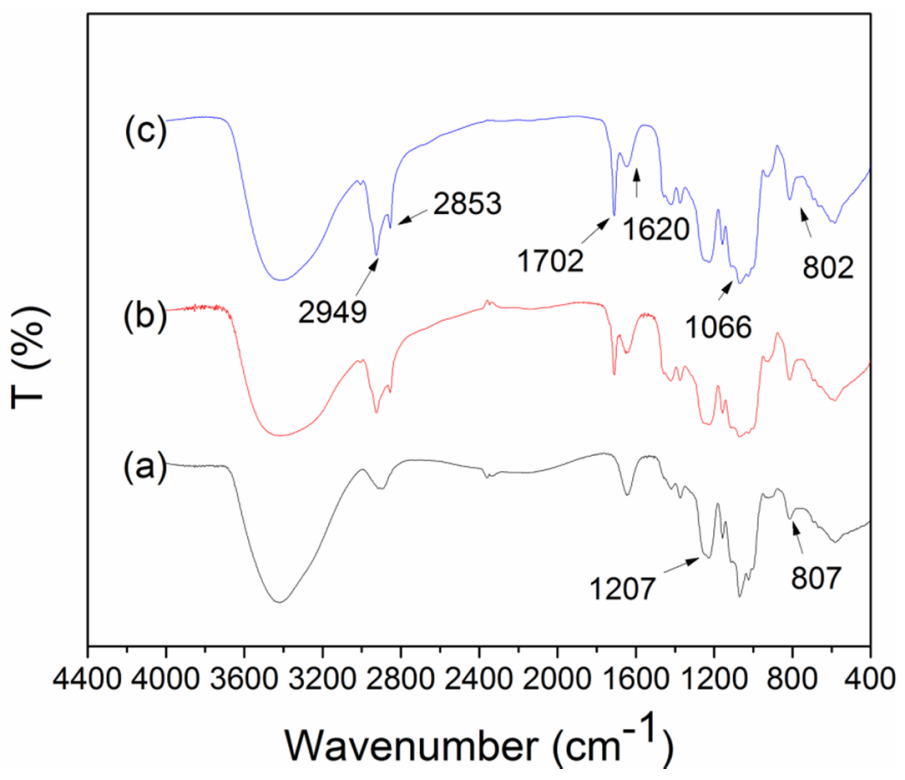

Figure 4. FTIR spectra of CS-OA films (a) $0 \%$; (b) 10\%; (c) $25 \%$ OA.

X-ray diffractogram (XRD) was used to investigate crystal structure, and assess the compatibility of CS and oleic acid. XRD of CS film with different contents of oleic acid blended were measured as shown in Figure 5. The XRD of CS film and CS-OA film showed two main crystalline reflections at $7.9^{\circ}$ and $23.1^{\circ}$, presenting the characteristic of major amorphous structures for all films, which was similar with the fine structure of CMC [39]. No new diffraction peaks were observed in composite films, suggesting no intermolecular interactions between CS and OA.

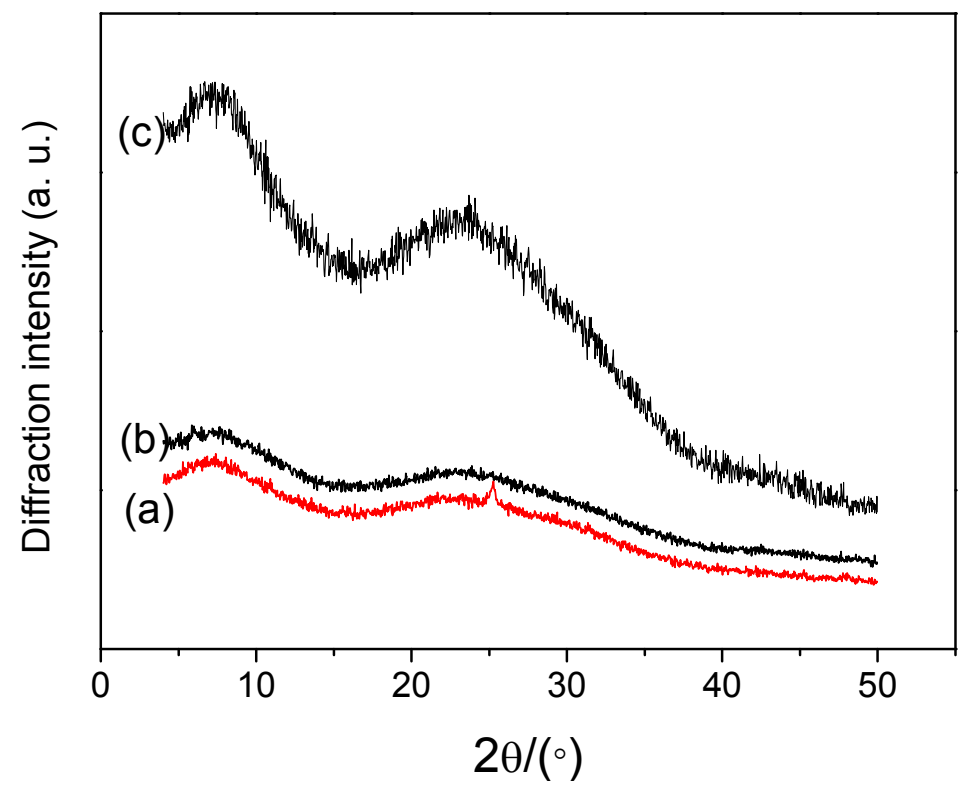

Figure 5. XRD patterns of CS-OA films (a) $0 \%$; (b) 10\%; (c) 25\% OA. 


\section{Experimental Section}

\subsection{Materials}

Cellulose sulfate (CS) was synthesized using heterogeneous method [17], with dynamic viscosity $\left(\eta_{2} \%, 2 \mathrm{wt} \%\right.$ solution) of $346 \mathrm{mPa} \cdot \mathrm{s}^{-1}$ and average substitution degree of 0.4 . Glycerol and oleic acid (OA, C18:1) were purchased from Sinopharm Chemical Reagent Co., Ltd. (China). Distilled water was used to form samples preparation.

\subsection{Preparation of Cellulose Sulfate Films}

Four different formulations based on cellulose sulfate (CS), glycerol (Gly) and oleic acid (OA) were prepared. CS ( $2 \mathrm{~g})$ and Gly $(0.3 \mathrm{~g})$ were dispersed in $100 \mathrm{~mL}$ water in order to obtain polysaccharide dispersions. The OA fraction was incorporated in a CS-OA ratio of 1:0.05, 1:0.10, 1:0.15, 1:0.2, 1:0.25 and the mixture was homogenized at $13,000 \mathrm{rpm}$ for $1 \mathrm{~min}$, under vacuum, using a rotor-stator homogenizer (Ultraturrax T25, Janke and Kunkel, Germany). Then the film forming dispersions were gently spread over a leveled Teflon plate (150 mm diameter, Wei Xin Instrument Co., Ltd., Yixing, China) with $0.18 \mathrm{~g} \mathrm{~cm}^{-2}$ and dried for approximately $4 \mathrm{~h}$ at $60{ }^{\circ} \mathrm{C}$ and $45 \% \mathrm{RH}$. Afterwards, the films were peeled from the casting surface and stored in desiccators at $75 \% \mathrm{RH}$ for further testing. All treatments were made in triplicate.

\subsection{Rheological Behavior of the Film Forming Emulsions}

The dynamic viscosity of the film-forming solution was measured at $30 \pm 0.5{ }^{\circ} \mathrm{C}$ with a NDJ-5S rheometer (model NDJ-5S, Fangrui Instrument Co. Ltd., Shanghai, China). The range of shear rate, $100-300 \mathrm{~s}^{-1}$, was used because it covered all the concentrations of the samples using the same coaxial cylinder device. Each sample was analyzed in triplicate.

\subsection{Fourier Transform Infrared Spectroscopy (FTIR)}

The FTIR transmission spectra of the film prepared was recorded on an instrument (Shimadzu FTIR 8400 S, Kyoto, Japan) in the wavenumber range of $4000-400 \mathrm{~cm}^{-1}$, using Attenuated Total Reflectance mode (ATR). Spectra were recorded at a resolution of $4 \mathrm{~cm}^{-1}$ and 400 scans were carried out to obtain a high signal-to-noise ratio spectrum.

\subsection{X-ray Diffraction}

X-ray diffraction (XRD) patterns of all samples were analyzed by a X'Pert PRO XRD system (PANalytical, Almelo, The Netherlands) at $25^{\circ} \mathrm{C}$ and $75 \% \mathrm{RH}$, between $2 \theta=10^{\circ}$ and $2 \theta=80^{\circ}$ using $\mathrm{K} \alpha \mathrm{Cu}$ radiation $(\lambda=1.542 \AA), 40 \mathrm{kV}$ and $40 \mathrm{~mA}$ with a step size of $4^{\circ}$. Samples were cut into $2 \mathrm{~cm}$ squares for analysis. 


\subsection{Film Thickness}

The thickness $(\delta)$ of the sample was measured (exactness of $\pm 0.001 \mathrm{~mm}$ ) by a digital external micrometer (Mitutoyo Co., Tokyo, Japan) at ten different points of the film. Samples were conditioned at $25{ }^{\circ} \mathrm{C}$ and $75 \% \mathrm{RH}$ (a saturated $\mathrm{NaCl}$ solution) for $24 \mathrm{~h}$ before they were measured.

\subsection{Scanning Electron Microscopy}

The samples were maintained in a desiccator with $\mathrm{P}_{2} \mathrm{O}_{5}$ for two weeks to ensure water in films completely removed. The cross-sections of the films were observed by cryofracture of films frozen in liquid $\mathrm{N}_{2}$. The microstructure of the film was analyzed using a scanning electron microscope (Hitachi S4800, Tokyo, Japan). Samples were fixed on a copper stubs, gold coated, and observed using an accelerating voltage of $5 \mathrm{kV}$.

\subsection{Mechanical Properties}

Tensile strength (TS) and elongation at break $(\varepsilon)$ of the film were measured using a Instron Universal Testing Machine (Instron Corp., model 5569, MA, USA) according to the standard method [40]. Test samples, $25 \mathrm{~mm} \times 100 \mathrm{~mm}$, were cut from each film and fixed with an initial grip separation of $30 \mathrm{~mm}$. Five replicates of each film were then pulled apart at crosshead speed of $20 \mathrm{~mm} / \mathrm{s}$ and preload of $2 \mathrm{~N}$. The average thickness of film was $25 \pm 2 \mu \mathrm{m}$. TS (MPa) was calculated by the Equation (1):

$$
\mathrm{TS}=\mathrm{F}_{\max } / \mathrm{A}
$$

where $\mathrm{F}_{\max }$ is the maximum force $(\mathrm{N})$ loaded on the specimen before pulling apart; $\mathrm{A}$ is the cross-sectional area $\left(\mathrm{m}^{2}\right)$ of the specimen. cis defined as the Equation (2):

$$
\varepsilon=\Delta \mathrm{L} / \mathrm{L}_{0} \times 100 \%
$$

where $\Delta \mathrm{L}$ is the film elongation at the moment of rupture $(\mathrm{mm})$ and $\mathrm{L}_{0}$ is the initial length between the grips.

\subsection{Water Vapor Permeability (WVP)}

WVP data were measured according to the standard ASTM method (1995) [41]. Test samples, $90 \times 90 \mathrm{~mm}$, were cut from each film and sealed on cups which was previously filled with fused anhydrous $\mathrm{CaCl}_{2}(\mathrm{RH}=0 \%)$. And then the cups were placed into a humidity chamber at $25{ }^{\circ} \mathrm{C}$ and $75 \%$ $\mathrm{RH}$ (saturated $\mathrm{NaCl}$ solution) for 3 days. The sealed cups were weighed periodically $( \pm 0.0001 \mathrm{~g})$ to calculate water vapor transported into the cup. The data, weight vs. time, was linearly regressed to calculate the slope. The water vapor transmission rate (WVTR) through the film was calculated from the slope $(\Delta \mathrm{w} / \Delta \mathrm{t})$ of the fitted line divided by the test area (A) as Equation (3), $\left(\mathrm{g} \mathrm{s}^{-1} \mathrm{~m}^{-2}\right)$.

$$
\mathrm{WVTR}=\Delta \mathrm{W} /(\Delta \mathrm{t} \cdot \mathrm{A})
$$

where $\mathrm{w}$ is the weight of water transported into the cup $(\mathrm{g}), \mathrm{t}$ is the time for weight change (s), A is the area exposed to water vapor transfer $\left(\mathrm{m}^{2}\right)$. The WVP $\left(\mathrm{gm}^{-1} \mathrm{~s}^{-1} \mathrm{~Pa}^{-1}\right)$ is calculated as Equation (4).

$$
\mathrm{WVP}=(\mathrm{WVTR} \times \delta) / \Delta \mathrm{p}
$$


where $\delta$ is the film thickness (m) and $\Delta \mathrm{p}$ is the water vapor partial pressure difference across the two sides of the film $\left(\Delta \mathrm{p}=\mathrm{p}\left(\mathrm{RH}_{2}-\mathrm{RH}_{1}\right)=2081.325 \mathrm{~Pa}\right.$, where $\mathrm{p}$ is the saturation vapor pressure of water at $\left.25^{\circ} \mathrm{C}, \mathrm{RH}_{2}=75 \%, \mathrm{RH}_{1}=0 \%\right)(\mathrm{Pa})$.

\subsection{Contact Angle}

Contact angle of the film was measured using a Video-Based Contact Angle Meter model OCA 20 (DataPhysics Instruments $\mathrm{GmbH}$, Filderstadt, Germany). A droplet of $3 \mu \mathrm{L}$ ultrapure water was dispensed on each film surface using a micro syringe. The contact angle was recorded by analyzing the shape of a sessile drop after it had been placed over the surface of each film at different time. Image analysis was carried out by SCA20 software. Each sample was tested with three drops and three measurements were conducted for each water drop.

\subsection{Flexibility}

The flexibility of the film was determined by a bending method [21]. Each sample was cut into the size of $20 \times 40 \mathrm{~mm}$ and folded completely at the middle. The film was positively and negatively folded in turn until the film appeared rupture. The flexibility was rated as poor (folding number $<20$ ), middle ( $20 \leq$ folding number $<50)$, good $(50 \leq$ folding number $<100)$ and excellent (folding number $\geq 100)$.

\subsection{Integrity}

The CS film was deemed as good integrity of there was no breakage during peeling from the petri dish and vice versa.

\subsection{Oil Permeability}

Oil permeability of the film was determined following Hu's method [42]. The mouth of a glass test-tube filled with $3 \mathrm{~g}$ soybean oil (interior diameter: $25 \mathrm{~mm}$, and outer diameter: $27 \mathrm{~mm}$ ) was covered with CS film $(50 \times 50 \mathrm{~mm})$ and sealed tightly. The tube was upside down on a piece of filter paper. The oil penetration was judged according to the infiltration of soybean oil on filter paper as time going. Each sample was observed in triple.

\subsection{Water Solubility}

The solubility of film in water was characterized by the resolve time of the film. The test sample was placed into deionized water at $25^{\circ} \mathrm{C}$ until it was completely dissolved. Three samples of each film were tested.

\subsection{Transparency}

Film specimen was cut into a rectangle piece $(20 \times 10 \mathrm{~mm})$ and attached on the wall of a test cell directly. The light transmission ( $\mathrm{T} \%$ ) of sample was measured at $560 \mathrm{~nm}$ using a UV-722 spectroscope (Rayleigh Corp., model 722, Beijing, China) and air was used as the reference. Three samples of each film were tested. 


\subsection{Statistical Analysis}

Data for each test were are presented as mean $\pm \mathrm{SD}$ after statistical analysis. The significance in the difference between factors and levels was evaluated by the analysis of variance (ANOVA). Comparison of the means was done employing a Tukey test to identify which groups were significantly different from others $(p<0.05)$.

\section{Conclusions}

The above findings indicated that the hydrophobicity of CS films can be regulated by incorporation of OA. The OA incorporation into CS film decreased the cohesive matrix of the film, which was severely affected by the size distribution of the OA droplet in film-forming solution. The solubility and transparence of the CS-OA decreased, while the thickness and oil permeability dramatically increased with the OA content increasing. Films with the addition of $\mathrm{OA}$ presented better water vapor barrier properties as compared to pure CS films. The WVP decreased from $3.92 \times 10^{-11}$ to $1.45 \times 10^{-11} \mathrm{gm}^{-1} \mathrm{~s}^{-1} \mathrm{~Pa}^{-1}$ when OA content varied from 0 to $30 \%$. The TS and E\% of the CS-OA film decreased, which indicated the film was more fragile than pure CS film. Films with a 1:0.15:0.15 CS:glycerol:OA ratio showed the most adequate functional properties when considering both tensile and water transport properties (TS: $43.5 \pm 1.3 \mathrm{MPa}$, E\%: $9.2 \pm 0.5$, WVP: $1.91 \pm 0.12 \times 10^{-11} \mathrm{~g} \mathrm{~m}^{-1} \mathrm{~s}^{-1} \mathrm{~Pa}^{-1}$ ).

\section{Acknowledgments}

The authors express their thanks for the support from the Nature Science Foundation of China (20906035), the Promotion Program for Young and Middle-aged Teacher in Science and Technology Research of Huaqiao University (ZQN-PY109) and fok ying-tong education foundation for young teachers (133037).

\section{Author Contributions}

Guo Chen and Jun Zhao conceived and designed the experiments; Bin Zhang performed the experiments; Bin Zhang and Guo Chen analyzed the data; Guo Chen contributed reagents/materials/analysis tools; Guo Chen and Bin Zhang wrote the paper.

\section{Conflicts of Interest}

The authors declare no conflict of interest.

\section{References}

1. Debeaufort, F.; Quezada-Gallo, J.A.; Voilley, A. Edible films and coatings: Tomorrow's packagings: A review. Crit. Rev. Food Sci. Nutr. 1998, 38, 299-313.

2. Jimenez, A.; Fabra, M.J.; Talens, P.; Chiralt, A. Edible and biodegradable starch films: A review. Food Bioprocess Technol. 2012, 5, 2058-2076.

3. Clasen, C.; Kulicke, W.M. Determination of viscoelastic and rheo-optical material functions of water-soluble cellulose derivatives. Progr. Polym. Sci. 2001, 26, 1839-1919. 
4. Ortega-Toro, R.; Jiménez, A.; Talens, P.; Chiralt, A. Properties of starch-hydroxypropyl methylcellulose based films obtained by compression molding. Carbohydr. Polym. 2014, 109, 155-165.

5. Slavutsky, A.M.; Bertuzzi, M.A. Water barrier properties of starch films reinforced with cellulose nanocrystals obtained from sugarcane bagasse. Carbohydr. Polym. 2014, 110, 53-61.

6. De Moura, M.R.; Lorevice, M.V.; Mattoso, L.H.C.; Zucolotto, V. Highly stable, edible cellulose films incorporating chitosan nanoparticles. J. Food Sci. 2011, 76, S25-S29.

7. Malmiri, H.J.; Osman, A.; Tan, C.P.; Rahman, R.A. Effects of edible surface coatings (sodium carboxymethyl cellulose, sodium caseinate and glycerol) on storage quality of berangan banana (musa sapientum cv. Berangan) using response surface methodology. J. Food Process. Preserv. 2012, 36, 252-261.

8. Wang, S.; Kuang, X.; Li, B.; Wu, X.; Huang, T. Physical properties and antimicrobial activity of chilled meat pads containing sodium carboxymethyl cellulose. J. Appl. Polym. Sci. 2013, 127, 612-619.

9. Arrieta, M.P.; Fortunati, E.; Dominici, F.; López, J.; Kenny, J.M. Bionanocomposite films based on plasticized pla-phb/cellulose nanocrystal blends. Carbohydr. Polym. 2015, 121, 265-275.

10. Fortunati, E.; Peltzer, M.; Armentano, I.; Torre, L.; Jiménez, A.; Kenny, J.M. Effects of modified cellulose nanocrystals on the barrier and migration properties of pla nano-biocomposites. Carbohydr. Polym. 2012, 90, 948-956.

11. Ayranci, E.; Tunc, S. A method for the measurement of the oxygen permeability and the development of edible films to reduce the rate of oxidative reactions in fresh foods. Food Chem. 2003, 80, 423-431.

12. Bravin, B.; Peressini, D.; Sensidoni, A. Development and application of polysaccharide-lipid edible coating to extend shelf-life of dry bakery products. J. Food Eng. 2006, 76, 280-290.

13. Navarro-Tarazaga, M.L.; Del Rio, M.A.; Krochta, J.M.; Perez-Gago, M.B. Fatty acid effect on hydroxypropyl methylcellulose-beeswax edible film properties and postharvest quality of coated 'ortanique' mandarins. J. Agric. Food Chem. 2008, 56, 10689-10696.

14. Navarro-Tarazaga, M.L.; Massa, A.; Perez-Gago, M.B. Effect of beeswax content on hydroxypropyl methylcellulose-based edible film properties and postharvest quality of coated plums (cv. Angeleno). Lwt-Food Sci. Technol. 2011, 44, 2328-2334.

15. Soazo, M.; Rubiolo, A.C.; Verdini, R.A. Effect of drying temperature and beeswax content on moisture isotherms of whey protein emulsion film. Procedia Food Sci. 2011, 1, 210-215.

16. Contreras-Oliva, A.; Rojas-Argudo, C.; Perez-Gago, M.B. Effect of solid content and composition of hydroxypropyl methylcellulose-lipid edible coatings on physico-chemical and nutritional quality of 'oronules' mandarins. J. Sci. Food Agric. 2012, 92, 794-802.

17. Chen, G.; Zhang, B.; Zhao, J.; Chen, H.W. Improved process for the production of cellulose sulfate using sulfuric acid/ethanol solution. Carbohydr. Polym. 2013, 95, 332-337.

18. Sanz-Nogues, C.; Horan, J.; Ryan, G.; Kassem, M.; O’Brien, T. Encapsulation of human mesenchymal stem cells in sodium cellulose sulfate-based microcapsules requires immortalization. Cytotherapy 2014, 16, S94.

19. Zhu, L.Y.; Yan, X.Q.; Zhang, H.M.; Lin, D.Q.; Yao, S.J.; Jiang, L. Determination of apparent drug permeability coefficients through chitosan-sodium cellulose sulfate polyelectrolyte complex films. Acta Phys.-Chim. Sin. 2014, 30, 365-370. 
20. Chen, G.; Liu, B.; Zhang, B. Characterization of composite hydrocolloid film based on sodium cellulose sulfate and cassava starch. J. Food Eng. 2014, 125, 105-111.

21. Chen, G.; Zhang, B.; Zhao, J.; Chen, H.W. Development and characterization of food packaging film from cellulose sulfate. Food Hydrocoll. 2014, 35, 476-483.

22. Chillo, S.; Flores, S.; Mastromatteo, M.; Conte, A.; Gerschenson, L.; Del Nobile, M.A. Influence of glycerol and chitosan on tapioca starch-based edible film properties. J. Food Eng. 2008, 88, $159-168$.

23. Camino, N.A.; Pilosof, A.M.R. Hydroxypropylmethylcellulose at the oil-water interface. Part ii. Submicron-emulsions as affected by ph. Food Hydrocoll. 2011, 25, 1051-1062.

24. Mitidieri, F.; Wagner, J. Coalescence of o/w emulsiones stabilized by whey and isolate soybean proteins. Influence of thermal denaturation, salt adittion and competitive interfacial adsorption. Food Res. Int. 2002, 35, 547-557.

25. Fabra, M.J.; Hambleton, A.; Talens, P.; Debeaufort, F.; Chiralt, A.; Voilley, A. Influence of interactions on water and aroma permeabilities of 1-carrageenan-oleic acid-beeswax films used for flavour encapsulation. Carbohydr. Polym. 2009, 76, 325-332.

26. Ghasemlou, M.; Khodaiyan, F.; Oromiehie, A.; Yarmand, M.S. Characterization of edible emulsified films with low affinity to water based on kefiran and oleic acid. Int. J. Biol. Macromol. 2011, 49, 378-384.

27. Limpisophon, K.; Tanaka, M.; Osako, K. Characterisation of gelatin-fatty acid emulsion films based on blue shark (prionace glauca) skin gelatin. Food Chem. 2010, 122, 1095-1101.

28. Hong, S.D.; Ha, M.Y.; Balachandar, S. Static and dynamic contact angles of water droplet on a solid surface using molecular dynamics simulation. J. Colloid Interface Sci. 2009, 339, 187-195.

29. Zahedi, Y.; Ghanbarzadeh, B.; Sedaghat, N. Physical properties of edible emulsified films based on pistachio globulin protein and fatty acids. J. Food Eng. 2010, 100, 102-108.

30. Bertan, L.C.; Tanada-Palmu, P.S.; Siani, A.C.; Grosso, C.R.F. Effect of fatty acids and 'brazilian elemi' on composite films based on gelatin. Food Hydrocoll. 2005, 19, 73-82.

31. Yang, L.; Paulson, A.T. Effects of lipids on mechanical and moisture barrier properties of edible gellan film. Food Res. Int. 2000, 33, 571-578.

32. Handa, A.; Gennadios, A.; Hanna, M.A.; Weller, C.L.; Kuroda, N. Physical and molecular properties of egg-white lipid films. J. Food Sci. 1999, 64, 860-864.

33. Shellhammer, T.H.; Krochta, J.M. Whey protein emulsion film performance as affected by lipid type and amount. J. Food Sci. 1997, 62, 390-394.

34. De la Caba, K.; Pena, C.; Ciannamea, E.M.; Stefani, P.M.; Mondragon, I.; Ruseckaite, R.A. Characterization of soybean protein concentrate-stearic acid/palmitic acid blend edible films. J. Appl. Polym. Sci. 2012, 124, 1796-1807.

35. Nobrega, M.M.; Olivato, J.B.; Muller, C.M.O.; Yamashita, F. Addition of saturated fatty acids to biodegradable films: Effect on the crystallinity and viscoelastic characteristics. J. Polym. Environ. 2013, 21, 166-171.

36. Rezvani, E.; Schleining, G.; Sumen, G.; Taherian, A.R. Assessment of physical and mechanical properties of sodium caseinate and stearic acid based film-forming emulsions and edible films. J. Food Eng. 2013, 116, 598-605. 
37. Fabra, M.J.; Talens, P.; Chiralt, A. Tensile properties and water vapor permeability of sodium caseinate films containing oleic acid-beeswax mixtures. J. Food Eng. 2008, 85, 393-400.

38. Wang, Z.; Zhou, J.; Wang, X.-X.; Zhang, N.; Sun, X.-X.; Ma, Z.-S. The effects of ultrasonic/microwave assisted treatment on the water vapor barrier properties of soybean protein isolate-based oleic acid/stearic acid blend edible films. Food Hydrocoll. 2014, 35, 51-58.

39. Martins, S.; Fernandes, J.B. A simple method to prepare high surface area activated carbon from carboxyl methyl cellulose by low temperature physical activation. J. Therm. Anal. Calorim. 2013, 112, 1007-1011.

40. American Society for Testing and Materials (ASTM). Standard test method for tensile properties of thin plastic sheeting. In Standard D882. Annual Book of American Standard Testing Methods; ASTM: Philadelphia, PA, USA, 2001.

41. American Society for Testing and Materials (ASTM). Standard test methods for water vapour transmission of materials. In Standards Designations: E96-95. In Annual Book of ASTM Standards; ASTM: Philadelphia, PA, USA, 1995; pp. 406-413.

42. $\mathrm{Hu}, \mathrm{G}$; Chen, J.; Gao, J. Preparation and characteristics of oxidized potato starch films. Carbohydr. Polym. 2009, 76, 291-298.

(C) 2015 by the authors; licensee MDPI, Basel, Switzerland. This article is an open access article distributed under the terms and conditions of the Creative Commons Attribution license (http://creativecommons.org/licenses/by/4.0/). 